\title{
Modelling fortification of corn masa flour with folic acid and the potential impact on Mexican-American women with lower acculturation
}

\author{
Heather C Hamner*, Sarah C Tinker, Alina L Flores, Joe Mulinare, Aliki P Weakland \\ and Nicole F Dowling \\ National Center on Birth Defects and Developmental Disabilities, Centers for Disease Control and Prevention \\ (CDC), 1600 Clifton Road NE, MS E-86, Atlanta, GA 30033, USA
}

Submitted 20 March 2012: Final revision received 31 July 2012: Accepted 7 August 2012: First published online 1 November 2012

\begin{abstract}
Objective: Hispanics with lower acculturation may be at higher risk for neural tube defects compared with those with higher acculturation due to lower total folic acid intake or other undetermined factors. Modelling has indicated that fortification of corn masa flour with folic acid could selectively target Mexican Americans more than other race/ethnicities. We assessed whether fortification of corn masa flour with folic acid could selectively increase folic acid intake among Mexican-American women with lower acculturation, as indicated by specific factors (language preference, country of origin, time living in the USA).

Design: We used dietary intake and dietary supplement data from the National Health and Nutrition Examination Survey 2001-2008, to estimate the amount of additional total folic acid that could be consumed if products considered to contain corn masa flour were fortified at $140 \mu \mathrm{g}$ of folic acid per $100 \mathrm{~g}$ of corn masa flour.

Setting: USA.

Subjects: Non-pregnant women aged 15-44 years ( $n$ 5369).

Results: Mexican-American women who reported speaking Spanish had a relative percentage change in usual daily total folic acid intake of $30 \cdot 5$ (95\% CI 27.8, 33.4) $\%$, compared with $8 \cdot 3$ (95\% CI 7.3, 9.4) \% for Mexican-American women who reported speaking English. We observed similar results for other acculturation factors. An increase of 6.0 percentage points in the number of Mexican-American women who would achieve the recommended intake of $\geq 400 \mu \mathrm{g}$ folic acid/d occurred with fortification of corn masa flour; compared with increases of $1 \cdot 1$ percentage points for non-Hispanic whites and 1.3 percentage points for non-Hispanic blacks. An even greater percentage point increase was observed among Mexican-American women who reported speaking Spanish (8.2).

Conclusions: Fortification of corn masa flour could selectively increase total folic acid intake among Mexican-American women, especially targeting MexicanAmerican women with lower acculturation, and result in a decrease in the number of pregnancies affected by neural tube defects.
\end{abstract}

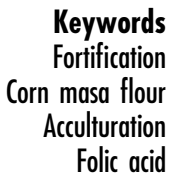

Keywords

Fortification

Acculturation

Folic acid
Randomized controlled trials have indicated that women who consume higher amounts of folic acid reduce their risk of having a pregnancy affected by neural tube defects $(\text { NTD })^{(1,2)}$. This led to recommendations by the US Public Health Service (1992) and the Institute of Medicine (1998) that women capable of becoming pregnant should consume $400 \mu \mathrm{g}$ of folic acid every day ${ }^{(3,4)}$. The US Food and Drug Administration mandated that by 1998 cereal grain products labelled as enriched (e.g. breads, pastas) be fortified with $140 \mu \mathrm{g}$ of folic acid per $100 \mathrm{~g}$ of flour in an effort to reduce the risk of NTD such as anencephaly and spina bifida among women of childbearing age ${ }^{(5)}$.
Since mandatory folic acid fortification, the prevalence of NTD has decreased by $36 \%$ in the $\mathrm{USA}^{(6)}$; however, the prevalence of NTD continues to be highest among Hispanic $\dagger$ women $^{(6,8,9)}$. Mexican-American and non-Hispanic white women have reported similar folic acid intakes from cereal grain products labelled as enriched, but total folic acid intakes - which include cereal grain products labelled as

$\uparrow$ The term 'Hispanic' is used for NTD because this is how the data are collected. However, folic acid intake data that can be generalized to the US population are available only for Mexican Americans. It should be noted that approximately $63 \%$ of all Hispanics in the USA are Mexican Americans ${ }^{(7)}$. 
enriched, ready-to-eat cereals (that can be voluntarily fortified up to $400 \mu \mathrm{g}$ per serving ${ }^{(10)}$ ) and supplements containing folic acid - are lower among MexicanAmerican women ${ }^{(11)}$. The disparity among MexicanAmerican women is more pronounced when total folic acid intake is stratified by factors that assess acculturation among Mexican-American women (e.g. language preference, country of origin or time living in the USA) ${ }^{(11)}$. The association of acculturation, a term used to describe the process in which two cultures combine with one another ${ }^{(12)}$, with the risk of NTD among the Hispanic population has been assessed. A recent case-control study found that the risk of spina bifida was higher among Hispanic women who reported speaking Spanish or reported being born in Mexico/Central America and residing in the USA for $<5$ years (i.e. proxies for lower acculturation) than among non-Hispanic white women ${ }^{(13)}$.

Corn masa flour, an ingredient that is used to make corn tortillas but is not currently fortified with folic acid, is consumed in large quantities by the Mexican and Central American populations ${ }^{(14)}$. Hamner et al. modelled the potential impact that fortification of corn masa flour with folic acid could have on total folic acid intake in the Mexican-American population $^{(15)}$. Results indicated that this intervention could selectively target the Mexican-American population more than other race/ethnicities ${ }^{(15)}$. However, their analysis did not differentiate Mexican Americans by acculturation status. The purpose of the current analysis was to assess whether fortification of corn masa flour could selectively target Mexican-American women with lower acculturation as defined by language preference, country of origin and time living in the USA.

\section{Materials and methods}

\section{National Health and Nutrition Examination Survey, 2001-2008*}

The National Health and Nutrition Examination Survey (NHANES) 2001-2008 was conducted using a stratified multistage probability design. The survey captured a nationally representative sample of the non-institutionalized civilian US population. Participants completed a household interview and a physical examination. For the current analysis, we used data from NHANES 2001-2008 excluding women who were pregnant or those whose dietary interview data did not meet minimum required standards for data quality on day 1 or day $2^{(16)}$. Analyses conducted by race/ ethnicity were restricted to non-Hispanic white, nonHispanic black and Mexican-American women because of the small numbers of women of other racial and ethnic groups. All participants in NHANES provided written

\footnotetext{
* The description of the Materials and methods was adapted directly from Hamner et $a l .{ }^{(15)}$. The analysis presented here includes four additional survey years (2005-2008) and any methodology or analytical changes as a result of these additional years are noted.
}

informed consent and the NHANES study received approval from the National Center for Health Statistics Ethical Review Board.

\section{Modelling of folic acid intake from corn masa flour}

Methods for modelling the impact of corn masa flour fortification on folic acid intake have been described previously $^{(15)}$. In summary, modelling entailed four main steps: (i) identification of foods that could contain corn masa flour; (ii) determination of the proportion of corn masa flour per food item by weight; (iii) determination of the amount of additional folic acid in each food item from corn masa flour fortified at $140 \mu \mathrm{g}$ of folic acid per $100 \mathrm{~g}$ of corn masa flour; and (iv) creation of modelled folic acid intake amounts with the additional folic acid intake from fortified corn masa flour.

As was done previously, foods reported in NHANES 2005-2008 were reviewed to identify those that could contain corn masa flour. An additional sixteen foods were added to the original foods identified and reported in $2001-2004^{(15)}$ and were validated by an international manufacturer of corn masa flour, resulting in 103 foods (see Appendix).

Sample calculations to determine the proportion of corn masa flour in each food item and how much additional folic acid would be added to products that could contain corn masa flour if fortified are available in Hamner et $a l .{ }^{(15)}$. The total amount of folic acid an individual would have consumed with folic acid fortification of corn masa flour included the estimated or expected intake from fortified corn masa flour as if it were fortified plus the actual reported folic acid intake from other foods and supplements.

\section{Folic acid intake from foods}

We obtained estimated intake of folic acid from foods using one $24 \mathrm{~h}$ dietary recall questionnaire in NHANES 2001-2002 and two $24 \mathrm{~h}$ dietary recall questionnaires for NHANES 2003-2008. To calculate nutrient intake from foods, we used the US Department of Agriculture Food and Nutrient Database for Dietary Studies version 1 for NHANES 2001-2002 ${ }^{(17)}$, version 2 for NHANES 2003-2004 ${ }^{(18)}$, version 3 for NHANES 2005-2006 ${ }^{(19)}$ and version $4 \cdot 1$ for NHANES $2007-2008^{(20)}$.

\section{Folic acid intake from supplements}

During each household interview in NHANES 2001-2008, participants were asked about their use of dietary supplements over the past $30 \mathrm{~d}$, including single vitamins, multivitamins, minerals, herbs and other similar nutritional substances, and were classified as a user if they reported taking such a supplement containing folic acid at least one time during the past $30 \mathrm{~d}$. We calculated the average daily folic acid intake from each supplement and added this estimate to the amount of folic acid consumed 
from foods for each day of intake for each individual ${ }^{(21)}$. In calculating usual total folic acid intake, average folic acid intake from supplements was added to foods and then usual intake was estimated using the Software for Intake Distribution Estimation (PC-SIDE).

\section{Acculturation factors}

NHANES includes data on several factors that can be used to classify acculturation. These variables are available for participants aged 12 years and older. Among individuals who identified themselves as Hispanic, NHANES recorded the primary language spoken at home. As has been done previously $^{(11)}$, we categorized language spoken at home into three levels: (i) women who reported speaking English all or most of the time; (ii) women who reported speaking an equal amount of English and Spanish; and (iii) women who reported speaking Spanish all or most of the time. Individuals were categorized as being born in the USA or Mexico for country of origin. Information on length of time living in the USA was categorized into $<5$ years, 5-14 years or $\geq 15$ years. For purposes of the current analysis, lower acculturation categories were defined by: (i) speaking Spanish all or most of the time; (ii) speaking an equal amount of Spanish and English; (iii) being born in Mexico; (iv) living in the USA for $<5$ years; or (v) living in the USA for 5-14 years. Acculturation factors were considered only for Mexican Americans.

\section{Analytic sample}

Of the 6210 non-pregnant women aged 15-44 years during the period 2001-2008, we excluded 778 women who did not meet the minimum data quality standard for dietary recall on day 1 (2001-2008) or day 2 of their dietary recall (2003-2008 only) because of incomplete dietary records. Additionally, we excluded women who were missing information on supplement use ( $n$ 63), resulting in a final sample size of 5369 non-pregnant women aged $15-44$ years ( $86 \%$ of the eligible sample). Compared with women included in the final analytic sample, to the extent data were available, excluded women were less likely to have reported consuming corn masa flour $\left(P<0 \cdot 05, \chi^{2}\right.$ test $)$; however, there were no differences by race/ethnicity or use of a folic acid-containing supplement.

\section{Statistical analysis}

We conducted analyses using usual daily total folic acid intake without and with the modelled addition of folic acid from corn masa flour fortification (referred to as 'current' and 'modelled', respectively, in the presentation of results) to assess the potential contribution that fortified corn masa flour could have on total folic acid intake. It has been reported that estimates of nutrient intake based on one day's worth of intake do not account for possible within-person variation, resulting in an overestimation of the variance in intake of a population ${ }^{(19,20)}$. Therefore, we used PC-SIDE version 1.02 (Iowa State University, Ames, IA, USA), which takes into account both between- and within-person variation when at least a sub-sample of the population has two or more days of intake data, as in NHANES 2001-2008, to estimate usual nutrient intake. Within-person variation estimates from NHANES 2003-2008 were used as an estimate for within-person variation in NHANES 2001-2002 data. Detailed descriptions of this method are published elsewhere $^{(22,23)}$.

We used PC-SIDE to estimate the distributions (percentiles) of usual daily total folic acid intake, as well as daily total energy intake. We estimated the percentage of a given population with usual daily total folic acid intake at or above the recommended $400 \mu \mathrm{g}$ of total folic acid. Analyses were conducted for all women aged 15-44 years, and stratified by race/ethnicity and acculturation factors. We used PC-SIDE to estimate the best linear unbiased predictor of usual daily total folic acid intake for each individual. The best linear unbiased predictors were used to estimate the relative percentage change between the median intake under the current scenario and the modelled scenario in which corn masa flour was fortified as described in Hamner et al. ${ }^{(15)}$.

We used SPSS Complex Samples Design version 18.0 to account for the survey design and to calculate all frequencies, $t$ tests, $\chi^{2}$ tests and relative percentage changes. We conducted all analyses using 8-year dietary weights calculated from day 1 dietary weights for the period 2001-2002 and day 2 dietary weights for the period 2003-2008, as recommended by the National Center for Health Statistics at the Centers for Disease Control and Prevention $^{(16)}$. For analyses conducted with PC-SIDE, we calculated standard errors using a set of 122 jackknife replicate weights. Replicate weights were calculated using a combination of day 1 dietary weights for NHANES 2001-2002 data and day 2 dietary weights for NHANES 2003-2008.

\section{Results}

Demographic characteristics of the sample are presented in Table 1. Mexican-American women were more likely to report consuming corn masa flour on either day 1 or day 2 of the survey as compared with non-Hispanic white women or non-Hispanic black women $(67 \cdot 2 \%, 27 \cdot 6 \%$ and $29 \cdot 6 \%$, respectively; $P<0 \cdot 05)$. Demographic characteristics of Mexican-American women by acculturation factors are reported in Table 2. Mexican-American women who reported lower acculturation factors were more likely to report consuming corn masa flour on either day 1 or day 2 of the survey as compared with Mexican-American women who reported higher acculturation factors $(P<0 \cdot 05)$. All percentages are weighted.

Estimates of current and modelled median usual daily intake of total folic acid for women of childbearing age are presented in Table 3. The current overall median usual 
Table 1 Demographic characteristics of women aged 15-44 years by race/ethnicity, NHANES 2001-2008

\begin{tabular}{|c|c|c|c|c|c|c|c|c|c|c|c|c|}
\hline & \multicolumn{3}{|c|}{ Total } & \multicolumn{3}{|c|}{ Non-Hispanic whiteł } & \multicolumn{3}{|c|}{ Non-Hispanic black } & \multicolumn{3}{|c|}{ Mexican American‡ } \\
\hline & Unweighted $n$ & $\%$ & $95 \% \mathrm{Cl}$ & Unweighted $n$ & $\%$ & $95 \% \mathrm{Cl}$ & Unweighted $n$ & $\%$ & $95 \% \mathrm{Cl}$ & Unweighted $n$ & $\%$ & $95 \% \mathrm{Cl}$ \\
\hline Women aged $15-44$ years (\%) & 5369 & - & - & 2065 & $65 \cdot 9$ & $61 \cdot 8,69 \cdot 8$ & 1384 & 13.5 & $11 \cdot 3,16 \cdot 2$ & 1362 & $10 \cdot 0$ & $8 \cdot 4,11 \cdot 9$ \\
\hline Folic acid supplement use $(\%)$ & 1292 & $31 \cdot 6$ & $29 \cdot 1,34 \cdot 2$ & 720 & $37 \cdot 1^{\star}$ & $33 \cdot 3,41 \cdot 0$ & 223 & $18 \cdot 7^{\star}$ & $15 \cdot 1,23 \cdot 0$ & 221 & $19 \cdot 1^{*}$ & $15 \cdot 9,22 \cdot 8$ \\
\hline Folic acid intake from supplements $\|,(\mu \mathrm{g} / \mathrm{d})$ & - & 380 & 357,403 & - & 391 & 364,419 & - & $315+$ & 255,374 & - & 345 & 272,418 \\
\hline Consumption of corn masa flour ${ }^{\star *}(\%)$ & 2083 & $32 \cdot 0$ & $29 \cdot 9,34 \cdot 2$ & 589 & $27 \cdot 6^{*}$ & $25 \cdot 1,30 \cdot 3$ & 413 & $29 \cdot 6^{*}$ & $26 \cdot 2,33 \cdot 3$ & 906 & $67 \cdot 2^{*}$ & $63 \cdot 0,71 \cdot 2$ \\
\hline Usual energy intakett $(\mathrm{kJ} / \mathrm{d})$ & 5369 & 7908 & 7518,8297 & 2065 & 7971 & 7514,8427 & 1384 & 7945 & 7682,8209 & 1362 & 8000 & 7460,8540 \\
\hline
\end{tabular}

NHANES, National Health and Nutrition Examination Survey.

*Significantly different by race/ethnicity (Pearson $\chi^{2}$ test): $P<0.05$.

tSignificantly different non-Hispanic whites $v$. non-Hispanic blacks ( $t$ test): $P<0.05$

‡Race/ethnicity sub-analyses were restricted to non-Hispanic whites, non-Hispanic blacks and Mexican Americans.

$\$$ Reported folic acid supplement use is defined as consuming a supplement containing folic acid in the previous $30 \mathrm{~d}$

IIReported folic acid supplement use is among supplement users only.

TValues are mean and $95 \%$ confidence interval.
${ }^{*}$ Reported consumption of corn masa flour is defined as consuming products that could contain corn masa flour on either day 1 or day 2 of the survey

t+Values are median and interquartile range.

Table 2 Demographic characteristics of Mexican-American women aged 15-44 years by acculturation factorsł, NHANES 2001-2008

\begin{tabular}{|c|c|c|c|c|c|c|c|c|c|c|c|c|c|c|c|c|}
\hline & \multicolumn{6}{|c|}{ Language preference } & \multicolumn{4}{|c|}{ Country of origin } & \multicolumn{6}{|c|}{ Time in the USA } \\
\hline & \multicolumn{2}{|c|}{$\begin{array}{l}\text { Spanish all or } \\
\text { most of the time }\end{array}$} & \multicolumn{2}{|c|}{$\begin{array}{l}\text { Equal Spanish } \\
\text { and English }\end{array}$} & \multicolumn{2}{|c|}{$\begin{array}{l}\text { English all or } \\
\text { most of the time }\end{array}$} & \multicolumn{2}{|c|}{ Mexico } & \multicolumn{2}{|r|}{ USA } & \multicolumn{2}{|c|}{$<5$ years } & \multicolumn{2}{|c|}{$5-14$ years } & \multicolumn{2}{|c|}{$\geq 15$ years } \\
\hline & $\%$ & $95 \% \mathrm{Cl}$ & $\%$ & $95 \% \mathrm{Cl}$ & $\%$ & $95 \% \mathrm{Cl}$ & $\%$ & $95 \% \mathrm{Cl}$ & $\%$ & $95 \% \mathrm{Cl}$ & $\%$ & $95 \% \mathrm{Cl}$ & $\%$ & $95 \% \mathrm{Cl}$ & $\%$ & $95 \% \mathrm{Cl}$ \\
\hline $\begin{array}{l}\text { Total (\%) } \\
\text { Unweighted } n\end{array}$ & $49 \cdot 6$ & $\begin{array}{l}44 \cdot 9,54 \cdot 4 \\
615\end{array}$ & $15 \cdot 4$ & $\begin{array}{l}12 \cdot 6,18 \cdot 7 \\
253\end{array}$ & $34 \cdot 9$ & $\begin{array}{l}30 \cdot 9,39 \cdot 2 \\
493\end{array}$ & $51 \cdot 4$ & $\begin{array}{l}45 \cdot 1,57 \cdot 6 \\
648\end{array}$ & $48 \cdot 3$ & $\begin{array}{l}42 \cdot 1,54 \cdot 6 \\
712\end{array}$ & $12 \cdot 1$ & $\begin{array}{l}8 \cdot 9,16 \cdot 3 \\
173\end{array}$ & $22 \cdot 8$ & $\begin{array}{l}19 \cdot 2,26 \cdot 9 \\
275\end{array}$ & $65 \cdot 1$ & $\begin{array}{l}60 \cdot 1,69 \cdot 8 \\
904\end{array}$ \\
\hline Folic acid supplement use $(\%)$ & $13 \cdot 8^{*}$ & $10 \cdot 1,18 \cdot 6$ & $14 \cdot 0$ & $8 \cdot 4,22 \cdot 4$ & $28 \cdot 8$ & $22 \cdot 0,36 \cdot 8$ & $15 \cdot 2^{*}$ & $12 \cdot 1,18 \cdot 8$ & $23 \cdot 3$ & $18 \cdot 2,29 \cdot 5$ & $8 \cdot 3^{*}$ & $5 \cdot 3,12 \cdot 6$ & $16 \cdot 5$ & $11 \cdot 2,23 \cdot 6$ & $22 \cdot 2$ & $17 \cdot 7,27 \cdot 6$ \\
\hline $\begin{array}{l}\text { Folic acid intake from } \\
\text { supplements\|, },(\mu \mathrm{g} / \mathrm{d})\end{array}$ & 356 & 274,438 & 381 & 198,563 & 329 & 219,440 & 360 & 279,441 & 335 & 234,435 & $224 t$ & 83,366 & 358 & 291,424 & 350 & 260,439 \\
\hline Consumption of corn masa flour** (\%) & $78 \cdot 5^{\star}$ & $74 \cdot 3,82 \cdot 2$ & $66 \cdot 5$ & $56 \cdot 3,75 \cdot 3$ & $51 \cdot 4$ & $44 \cdot 0,58 \cdot 8$ & $79 \cdot 5^{*}$ & $75 \cdot 1,83 \cdot 3$ & $54 \cdot 0$ & $47 \cdot 1,60 \cdot 8$ & $77 \cdot 9^{*}$ & $68 \cdot 9,84 \cdot 9$ & $83 \cdot 7$ & $77 \cdot 1,88 \cdot 6$ & $59 \cdot 2$ & $53 \cdot 9,64 \cdot 3$ \\
\hline Usual energy intakett $(\mathrm{kJ} / \mathrm{d})$ & 7753 & 7084,8422 & 8975 & 7820,10129 & 7983 & 7104,8862 & 7837 & 7414,8529 & 8230 & 7351,9109 & 7916 & 6414,9418 & 7908 & 7309,8506 & 8067 & 7075,9058 \\
\hline
\end{tabular}

NHANES, National Health and Nutrition Examination Survey.

Significantly different by acculturation factor (Pearson $\chi^{2}$ test): $P<0.05$.

+Significantly different $<5$ years $v$. $5-14$ years and $<5$ years $v$. $\geq 15$ years $(t$ test): $P<0.05$

‡Acculturation sub-analyses were restricted to Mexican Americans. Unweighted $n$ might not add up to total number of Mexican-American women because of missing data in acculturation factors.

\$Reported folic acid supplement use is defined as consuming a supplement containing folic acid in the previous $30 \mathrm{~d}$.

Reported folic acid supplement use is among supplement users only.

iValues are mean and $95 \%$ confidence interval.

${ }^{*}$ Reported consumption of corn masa flour is defined as consuming products that could contain corn masa flour on either day 1 or day 2 of the survey.

ttValues are median and interquartile range. 
Table 3 Median usual daily total folic acid intake with (modelled) and without (current) folic acid fortification of corn masa flour for women aged 15-44 years by race/ethnicity and age, NHANES 2001-2008¥

\begin{tabular}{|c|c|c|c|c|c|c|c|}
\hline & \multirow[b]{2}{*}{ Unweighted $n$} & \multicolumn{2}{|c|}{$\begin{array}{l}\text { Current usual } \\
\text { intake }(\mu \mathrm{g} / \mathrm{d})\end{array}$} & \multicolumn{2}{|c|}{$\begin{array}{l}\text { Modelled usual } \\
\text { intake }(\mu \mathrm{g} / \mathrm{d})\end{array}$} & \multicolumn{2}{|c|}{$\begin{array}{l}\text { Relative percentage } \\
\text { change }(\%)\end{array}$} \\
\hline & & Median & $95 \% \mathrm{Cl}$ & Median & $95 \% \mathrm{Cl}$ & Median & $95 \% \mathrm{Cl}$ \\
\hline \multirow{2}{*}{\multicolumn{8}{|c|}{ Race/ethnicity\| }} \\
\hline & & & & & & & \\
\hline Non-Hispanic white & 2065 & 263 & 239,287 & 274 & 248,300 & $3 \cdot 9$ & $3 \cdot 3,4 \cdot 4$ \\
\hline Non-Hispanic black & 1384 & 186 & 155,217 & 197 & 163,231 & $4 \cdot 6$ & $4 \cdot 1,5 \cdot 1$ \\
\hline Mexican American & 1362 & 202 & 167,237 & 243 & 209,277 & $21 \cdot 0$ & $18 \cdot 7,23 \cdot 3$ \\
\hline \multicolumn{8}{|l|}{ Acculturation factors } \\
\hline \multicolumn{8}{|l|}{ Language preference } \\
\hline Spanish all or most of the time & 615 & 191 & 146,236 & 247 & 205,289 & $30 \cdot 5$ & $27 \cdot 8,33 \cdot 4$ \\
\hline Equal Spanish and English & 253 & 185 & 151,219 & 225 & 189,261 & $22 \cdot 0$ & $20 \cdot 2,23 \cdot 8$ \\
\hline English all or most of the time & 493 & 218 & 154,282 & 241 & 186,296 & $8 \cdot 3$ & $7 \cdot 3,9 \cdot 4$ \\
\hline \multicolumn{8}{|l|}{ Country of origin } \\
\hline Mexico & 648 & 196 & 154,238 & 252 & 210,294 & $29 \cdot 9$ & $26 \cdot 9,33 \cdot 0$ \\
\hline USA & 712 & 210 & 180,240 & 234 & 208,260 & $10 \cdot 8$ & $9 \cdot 2,12 \cdot 3$ \\
\hline \multicolumn{8}{|l|}{ Time living in the USA } \\
\hline$<5$ years & 173 & 161 & 122,200 & 230 & 186,274 & $45 \cdot 1$ & $39 \cdot 7,50 \cdot 7$ \\
\hline $5-14$ years & 275 & 205 & 154,256 & 271 & 207,335 & $33 \cdot 7$ & $29 \cdot 7,37 \cdot 8$ \\
\hline$\geq 15$ years & 904 & 210 & 174,246 & 239 & 200,278 & $13 \cdot 1$ & $11 \cdot 3,15 \cdot 0$ \\
\hline
\end{tabular}

NHANES, National Health and Nutrition Examination Survey.

‡Data are adjusted for intake day of the week and interview method (in person or by telephone).

\$The relative percentage change was the antilog of the difference in the log of modelled intake minus the log of the current intake.

॥Race/ethnicity sub-analyses were restricted to non-Hispanic whites, non-Hispanic blacks and Mexican Americans.

$\uparrow$ Acculturation sub-analyses were restricted to Mexican Americans. Unweighted $n$ might not add up to total number of Mexican-American women because of missing data in acculturation factors.

daily intake of total folic acid was 244 (95\% CI 230, 258) $\mu \mathrm{g}$, which could increase to 257 (95\% CI 244, 270) $\mu \mathrm{g}$ with fortification of corn masa flour. This represents a relative percentage change of $3 \cdot 7(95 \%$ CI $3 \cdot 1,4 \cdot 2) \%$.

Non-Hispanic white women had higher 263 (95\% CI $239,287) \mu \mathrm{g}$ ) current median usual daily intake of total folic acid than either non-Hispanic black women (186 (95\% CI $155,217) \mu \mathrm{g})$ or Mexican-American women $(202(95 \% \mathrm{CI}$ $167,237) \mu \mathrm{g}$ ). In addition, non-Hispanic white women had higher modelled median usual daily intake of total folic acid than either non-Hispanic black women or MexicanAmerican women $(274$ (95\% CI 248, 300) $\mu \mathrm{g}, 197$ (95\% CI $163,231) \mu \mathrm{g}$ and $243(95 \%$ CI 209, 277) $\mu \mathrm{g}$, respectively). Mexican-American women had the largest absolute and relative percentage increases, with $41 \mu \mathrm{g}$ and $21.0 \%$, respectively, compared with non-Hispanic white women (11 $\mu \mathrm{g}$ and $3 \cdot 9 \%$, respectively) and non-Hispanic black women (11 $\mu \mathrm{g}$ and $4 \cdot 6 \%$, respectively).

Mexican-American women who reported lower acculturation factors had lower current median usual daily intake of total folic acid than Mexican-American women who reported higher acculturation factors. These differences were attenuated with fortification of corn masa flour. Mexican-American women who reported speaking Spanish all or most of the time had current median usual daily intake of total folic acid of 191 (95\% CI 146, 236) $\mu \mathrm{g}$ and those who reported speaking English all or most of the time had current median usual daily intake of total folic acid of $218(95 \%$ CI 154, 282) $\mu \mathrm{g}$. With fortification of corn masa flour, the modelled median usual daily intake of total folic acid for Mexican-American women who reported speaking Spanish all or most of the time could increase by $56 \mu \mathrm{g}$ to $247(95 \%$ CI 205, 289) $\mu \mathrm{g}$, while for those who reported speaking English all or most of the time the modelled median usual daily intake of total folic acid could increase by half that amount, $23 \mu \mathrm{g}$, to 241 (95\% CI 186, 296) $\mu \mathrm{g}$. The relative percentage change for Mexican-American women who reported speaking Spanish all or most of the time was 30.5 (95\% CI $27 \cdot 8$, $33 \cdot 4) \%$, compared with an $8 \cdot 3(95 \%$ CI $7 \cdot 3,9 \cdot 4) \%$ relative percentage change for Mexican-American women who reported speaking English all or most of the time. Similar relative percentage changes were observed for Mexican-American women with lower acculturation (i.e. women who reported speaking equal Spanish and English, in the USA for $<5$ years, in the USA for 5-14 years and born in Mexico).

We estimated the percentage of women of childbearing age with usual daily total folic acid intake at or above the recommended $400 \mu \mathrm{g}$ for current and modelled folic acid intake levels (Table 4). Among all women aged 15-44 years, $24 \cdot 0$ (95\% CI 21.4, 26.7) \% had usual daily intake of total folic acid $\geq 400 \mu \mathrm{g}$ under the current scenario, which could increase to 26.0 (95\% CI $23 \cdot 4,28 \cdot 6$ ) \% with fortification of corn masa flour. Mexican-American women had a much larger increase in the percentage of women achieving the recommendation for total folic acid. An estimated 13.0 (95\% CI $7 \cdot 8,18 \cdot 2) \%$ of Mexican-American women were consuming $\geq 400 \mu \mathrm{g}$ of total folic acid/d under the current scenario, which could increase to $19 \cdot 0$ (95\% CI $11 \cdot 1$, $26 \cdot 8) \%$, an increase of 6.0 percentage points, with 
Table 4 Percentage of women aged 15-44 years who would achieve the recommended intake of total folic acid (400 $\mu \mathrm{g} / \mathrm{d})$ with (modelled) and without (current) folic acid fortification of corn masa flour by race/ethnicity and acculturation factors, NHANES 2001-2008‡

\begin{tabular}{|c|c|c|c|c|c|}
\hline & \multirow[b]{2}{*}{ Unweighted $(n)$} & \multicolumn{2}{|c|}{$\begin{array}{c}\text { Current usual intake } \\
(\geq 400 \mu \mathrm{g} \text { of total folic acid/d) }\end{array}$} & \multicolumn{2}{|c|}{$\begin{array}{c}\text { Modelled usual intake } \\
(\geq 400 \mu \mathrm{g} \text { of total folic acid/d) }\end{array}$} \\
\hline & & $\%$ & $95 \% \mathrm{Cl}$ & $\%$ & $95 \% \mathrm{Cl}$ \\
\hline Total & 5369 & $24 \cdot 0$ & $21 \cdot 4,26 \cdot 7$ & $26 \cdot 0$ & $23 \cdot 4,28 \cdot 6$ \\
\hline \multicolumn{6}{|l|}{ Race/ethnicity§ } \\
\hline Non-Hispanic white & 2065 & $29 \cdot 6$ & $25 \cdot 7,33 \cdot 4$ & $30 \cdot 7$ & $26 \cdot 6,34 \cdot 8$ \\
\hline Non-Hispanic black & 1384 & $10 \cdot 3$ & $6 \cdot 7,14 \cdot 0$ & $11 \cdot 6$ & $6 \cdot 7,16 \cdot 6$ \\
\hline Mexican American & 1362 & $13 \cdot 0$ & $7 \cdot 8,18 \cdot 2$ & $19 \cdot 0$ & $11 \cdot 1,26 \cdot 8$ \\
\hline \multicolumn{6}{|l|}{ Acculturation factors $\|$} \\
\hline \multicolumn{6}{|l|}{ Language preference } \\
\hline Spanish all or most of the time & 615 & $9 \cdot 2$ & $5 \cdot 6,12 \cdot 9$ & $17 \cdot 4^{\star}$ & $10 \cdot 0,24 \cdot 9$ \\
\hline Equal Spanish and English & 253 & $4 \cdot 5$ & $0,10 \cdot 4$ & $10 \cdot 3$ & $0 \cdot 8,19 \cdot 8$ \\
\hline English all or most of the time & 493 & $20 \cdot 3$ & $7 \cdot 3,33 \cdot 3$ & $22 \cdot 9$ & $9 \cdot 2,36 \cdot 6$ \\
\hline \multicolumn{6}{|l|}{ Country of origin } \\
\hline Mexico & 648 & $11 \cdot 1$ & $6 \cdot 1,16 \cdot 0$ & $19 \cdot 5$ & $10 \cdot 1,28 \cdot 9$ \\
\hline USA & 712 & $15 \cdot 3$ & $8 \cdot 1,22 \cdot 4$ & $18 \cdot 6$ & $12 \cdot 4,24 \cdot 8$ \\
\hline \multicolumn{6}{|l|}{ Time living in the USA } \\
\hline$<5$ years & 173 & $5 \cdot 0$ & $0,13 \cdot 2$ & $11 \cdot 2$ & $3 \cdot 4,19 \cdot 0$ \\
\hline $5-14$ years & 275 & $10 \cdot 5$ & $2 \cdot 2,18 \cdot 7$ & $23 \cdot 0$ & $4 \cdot 6,41 \cdot 4$ \\
\hline$\geq 15$ years & 904 & $14 \cdot 6$ & $6 \cdot 3,22 \cdot 8$ & $18 \cdot 7$ & $10 \cdot 2,27 \cdot 3$ \\
\hline
\end{tabular}

fortification of corn masa flour. Comparatively, nonHispanic white women could have a $1 \cdot 1$ percentage point increase in the percentage with intake of total folic acid $\geq 400 \mu \mathrm{g} / \mathrm{d}$ (current: $29 \cdot 6$ (95\% CI $25 \cdot 7,33 \cdot 4$ ) \%; modelled: $30 \cdot 7$ (95\% CI 26.6, 34.8) \% and non-Hispanic black women could have a 1.3 percentage point increase (current: $10 \cdot 3$ (95\% CI $6 \cdot 7,14 \cdot 0) \%$; modelled: $11 \cdot 6(95 \%$ CI $6 \cdot 7,16 \cdot 6) \%)$.

Generally, Mexican-American women who had lower acculturation factors tended to have a larger increase in the percentage with usual daily intake of total folic acid $\geq 400 \mu \mathrm{g}$ with fortification of corn masa flour. Among Mexican-American women who reported speaking Spanish all or most of the time, 9.2 (95\% CI 5.6, 12.9) \% were achieving the recommendation for total folic acid under the current scenario, and this could increase by $8 \cdot 2$ percentage points to $17 \cdot 4$ (95\% CI $10 \cdot 0,24 \cdot 9) \%$ with fortification of corn masa flour, a statistically significant increase $(P=0 \cdot 026)$. Comparatively, among MexicanAmerican women who reported speaking English all or most of the time, $20 \cdot 3(95 \% \mathrm{CI} 7 \cdot 3,33 \cdot 3) \%$ were achieving the recommendation for total folic acid under the current scenario, which could increase by 2.6 percentage points to $22.9(95 \%$ CI $9 \cdot 2,36 \cdot 6) \%$ with fortification of corn masa flour. When stratified by country of origin and time living in the USA, Mexican-American women who reported being born in Mexico or living in the USA for $<5$ years or 5-14 years had larger percentage point increases for achieving the recommendation for total folic acid intake, as compared with their higher acculturated counterparts, with fortification of corn masa flour.

\section{Discussion}

The current analysis builds on the earlier modelling exercise from Hamner et $a l^{(15)}$ and assesses the impact of fortification of corn masa flour with folic acid on the segments of the Mexican-American population with the lowest folic acid intake ${ }^{(11)}$ and the highest prevalence of NTD-affected pregnancies, namely Mexican-American women with lower acculturation ${ }^{(6,8,9,13,24,25)}$. Overall, the modelling suggests that fortification of corn masa flour could substantially increase the total folic acid intake among Mexican-American women with lower acculturation compared with those with higher acculturation. Disparities in total folic acid intake between Mexican-American and non-Hispanic white women and between MexicanAmerican women with lower $v$. higher acculturation could be lessened if corn masa flour is fortified at $140 \mu \mathrm{g}$ of folic acid per $100 \mathrm{~g}$ of corn masa flour. Additionally, fortification of corn masa flour could shift the population distribution of total folic acid intake and could increase the percentage of women of childbearing age with usual daily intake of total folic acid $\geq 400 \mu \mathrm{g}$, with a larger increase among Mexican-American women with lower acculturation. Ultimately, this public health intervention could lead to a reduction in the risk of NTD for Hispanics.

Our analysis is subject to several limitations. The measurement of acculturation was based on individual questions and not from a validated acculturation scale. However, researchers have found that language preference can explain the majority of variation in validated scales ${ }^{(26,27)}$, making this a reasonable proxy measure. We could only 
estimate which foods could contain corn masa flour because this commodity was not specifically available in the MyPyramid Equivalents database. However, these foods were independently validated by a manufacturer of corn masa flour. The amount of folic acid added to each food was based on a fortification level which would result in a final product containing $140 \mu \mathrm{g}$ per $100 \mathrm{~g}$ of corn masa flour and with the assumption that all products that could contain corn masa flour were fortified at this amount. Estimates did not take into account any losses in folic acid level that might occur in corn masa flour during processing; thus, these estimates might be an overestimate of folic acid intake.

According to the 2010 US Census, there are over 50 million individuals in the USA who report being of Hispanic or Latino origin; $63 \%$ of these individuals are Mexican American $^{(7)}$. Based on data from 2005-2009, the population of Hispanic women of childbearing age is also increasing, with over 10 million Hispanic women aged 15-44 years ${ }^{(28)}$. Hispanic women accounted for approximately 1 million births in the USA in $2008^{(29)}$. Further, Hispanic women have higher birth rates, higher fertility rates, are younger at first pregnancy and have children at a later age than their non-Hispanic counterparts ${ }^{(29)}$. Although the prevalence of NTD has decreased in the USA since mandatory folic acid fortification ${ }^{(6)}$ and the disparity in NTD prevalence between Hispanic women and non-Hispanic white women has lessened, data indicate that Hispanic women continue to have the highest risk of having an NTD-affected pregnancy ${ }^{(6,8)}$. Using data from twenty-five population-based surveillance systems from 2005-2007, Hispanic women were estimated to be $1 \cdot 21(95 \%$ CI $1 \cdot 11,1 \cdot 31)$ times more at risk for an NTDaffected pregnancy than non-Hispanic white women ${ }^{(6)}$. Other researchers have also suggested that acculturation could be a risk factor for $\mathrm{NTD}^{(13,24,25)}$. However, this relationship has not been reported consistently and has been shown to vary for other birth defects ${ }^{(24)}$. Mexican-American women, and specifically those with lower acculturation, have lower total folic acid intake than non-Hispanic white women $^{(11)}$. Given that the number of Hispanic women is increasing, that these women have a higher pregnancy rate, birth rate and risk of NTD, and that Mexican-American women, specifically those with lower acculturation, have a lower total folic acid intake and possibly are at higher risk for NTD, fortification of corn masa flour with folic acid could have a significant public health impact. For example, an additional $6 \%$ of Mexican-American women consuming the recommended amount of folic acid means that almost 422000 women could be impacted ${ }^{(28)}$. Given these disparities and the potential for a large number of women to be affected, providing another opportunity for Hispanic women, and in particular for Hispanic women with lower acculturation, to consume folic acid could lessen the number of pregnancies affected by these serious birth defects.

In the current analysis, we estimated that MexicanAmerican women with lower acculturation were more likely to report consuming corn masa flour products than those with higher acculturation, resulting in the most vulnerable group of Mexican-American women being selectively targeted by a corn masa flour fortification initiative. Higher consumption of corn masa flour products among less acculturated Mexican Americans could be the result of having similar eating patterns to their native culture, which relies heavily on corn masa flour products such as corn tortillas ${ }^{(14)}$. Mexican Americans who are more acculturated may be more likely to have eating patterns that are more similar to the dominant US culture, which relies less heavily on corn masa flour products ${ }^{(30-32)}$.

Previous public health campaigns targeting Hispanic women have proved to be difficult and costly. There is evidence that paid media and health education/ communication campaigns targeting Spanish-speaking Hispanic women resulted in only small increases in women's consumption of a folic acid supplement ${ }^{(33)}$. Other interventions include the use of promotoras, or lay community health workers, in an effort to reach women on a one-to-one basis ${ }^{(34,35)}$. However, paid campaigns such as these are costly, difficult to sustain and localized in scope and geographic area. Thus, public health professionals need to utilize other possible interventions, such as fortification, to increase total folic acid intake without requiring behaviour changes.

Fortification of corn masa flour is a policy-level intervention that would not require sustained behaviour change and could result in a decreased prevalence of NTD. Given that the estimated total lifetime direct cost of a child born with spina bifida is \$US 560000 (2003 dollars) ${ }^{(36)}$, additional babies being born healthy could provide substantial financial return on investment to fortify corn masa flour with folic acid. Regardless of financial considerations, spina bifida is a debilitating lifelong condition placing a severe health and emotional burden on those affected and their families ${ }^{(37)}$.

\section{Conclusions and recommendations}

Fortification of corn masa flour with folic acid could selectively target Mexican-American women, particularly those with lower acculturation factors. Fortification of corn masa flour could reduce the disparity in total folic acid intake between Mexican-American women with lower and higher acculturation, shift the distribution of total folic acid intake, and ensure that more women achieve the recommended intake of $400 \mu \mathrm{g}$ of folic acid every day to prevent NTD. Fortification of corn masa flour is a policy-level intervention with the potential for significant public health impact.

\section{Acknowledgements}

Sources of funding: The research was funded by the US Centers for Disease Control and Prevention. The findings 
and conclusions in this report are those of the authors and do not necessarily represent the official position of the Centers for Disease Control and Prevention. Conflicts of interest: The authors report no conflicts of interest. Authors' contributions: Each author contributed to the development of this work. H.C.H. and S.C.T. designed the research; H.C.H. and S.C.T. analysed the data and performed the statistical analysis; H.C.H. and S.C.T. wrote the paper. H.C.H. had primary responsibility for final content. All authors have read and approved the final manuscript.

\section{References}

1. MRC Vitamin Study Research Group (1991) Prevention of neural tube defects: results of the Medical Research Council Vitamin Study. Lancet 338, 131-137.

2. Czeizel AE \& Dudas I (1992) Prevention of the first occurrence of neural-tube defects by periconceptional vitamin supplementation. $N$ Engl J Med 327, 1832-1835.

3. Centers for Disease Control and Prevention (1992) Recommendations for the use of folic acid to reduce the number of cases of spina bifida and other neural tube defects. MMWR Morb Mortal Wkly Rep 41, 1-7.

4. Institute of Medicine (1998) Dietary Reference Intakes for Thiamin, Riboflavin, Niacin, Vitamin $B_{6}$, Folate, Vitamin $B_{12}$, Pantothenic Acid, Biotin, and Choline. Washington, DC: National Academy Press.

5. Food and Drug Administration (1996) Food standards: amendment of standards of identity for enriched grain products to require addition of folic acid, final rule. Federal Register 61, 8781-8797.

6. Centers for Disease Control and Prevention (2010) CDC Grand Rounds: additional opportunities to prevent neural tube defects with folic acid fortification. MMWR Morb Mortal Wkly Rep 59, 980-984.

7. Ennis SR, Rios-Vargas M \& Albert NG (2011) The Hispanic Population: 2010. 2010 Census Briefs. Washington, DC: US Census Bureau.

8. Boulet SL, Yang Q, Mai C et al. (2008) Trends in the postfortification prevalence of spina bifida and anencephaly in the United States. Birth Defects Res Part A Clin Mol Teratol 82, 527-532.

9. Williams LJ, Rasmussen SA, Flores A et al. (2005) Decline in the prevalence of spina bifida and anencephaly by race/ ethnicity: 1995-2002. Pediatrics 116, 580-586.

10. Food and Drug Administration (1996) Food additives permitted for direct addition to food for human consumption; folic acid (folacin), final rule. Federal Register 61, $8797-8807$

11. Hamner HC, Cogswell ME \& Johnson MA (2011) Acculturation factors are associated with folate intakes among Mexican American women. J Nutr 141, 1889-1897.

12. Cabassa LJ (2003) Measuring acculturation: where we are and where we need to go. Hisp J Behav Sci 25, 127-146.

13. Canfield MA, Ramadhani TA, Shaw GM et al. (2009) Anencephaly and spina bifida among Hispanics: maternal, sociodemographic, and acculturation factors in the National Birth Defects Prevention Study. Birth Defects Res Part A Clin Mol Teratol 85, 637-646.

14. Bressani R, Rooney LW \& Serna Saldivar SO (1997) Fortification of Corn Masa Flour with Iron and/or Other Nutrients: A Literature and Industry Experience Review. Washington, DC: SUSTAIN.

15. Hamner HC, Mulinare J, Cogswell ME et al. (2009) Predicted contribution of folic acid fortification of corn masa flour to the usual folic acid intake for the US population: National Health and Nutrition Examination Survey, 2001-2004. Am J Clin Nutr 89, 305-315.

16. National Center for Health Statistics (2006) Analytic and Reporting Guidelines. Hyattsville, MD: Centers for Disease Control and Prevention.

17. US Department of Agriculture (2004) USDA Food and Nutrient Database for Dietary Studies, 1.O. Beltsville, MD: Agricultural Research Service, Food Surveys Research Group; available at http://www.ars.usda.gov/Services/docs. htm?docid $=12082$

18. US Department of Agriculture (2006) USDA Food and Nutrient Database for Dietary Studies, 2.O. Beltsville, MD: Agricultural Research Service, Food Surveys Research Group; available at http://www.ars.usda.gov/Services/docs. htm?docid $=12083$

19. US Department of Agriculture (2008) USDA Food and Nutrient Database for Dietary Studies, 3.O. Beltsville, MD: Agricultural Research Service, Food Surveys Research Group; available at http://www.ars.usda.gov/Services/docs. htm?docid $=17031$

20. US Department of Agriculture (2010) USDA Food and Nutrient Database for Dietary Studies, 4.1. Beltsville, MD: Agricultural Research Service, Food Surveys Research Group; available at http://www.ars.usda.gov/Services/docs. htm?docid $=20511$

21. Yang Q, Carter HK, Mulinare J et al. (2007) Race/ethnicity differences in folic acid intake among women of childbearing age in the United States after folic acid fortification: findings from the National Health and Nutrition Examination Survey, 2001-2002. Am J Clin Nutr 85, 1409-1416.

22. Carriquiry AL (2003) Estimation of usual intake distributions of nutrients and foods. J Nutr 133, issue 2, 601S-608S.

23. Guenther PM, Kott PS \& Carriquiry AL (1997) Development of an approach for estimating usual nutrient intake distribution at the population level. J Nutr 127, 1106-1112.

24. Ramadhani TA, Short V, Canfield MA et al. (2009) Are birth defects among Hispanics related to maternal nativity or number of years lived in the United States? Birth Defects Res Part A Clin Mol Teratol 85, 755-763.

25. Velie EM, Shaw GM, Malcoe LH et al. (2006) Understanding the increased risk of neural tube defect affected pregnancies among Mexico-born women in California: immigration and anthropometric factors. Paediatr Perinat Epidemiol 20, 219-230.

26. Marin G, Sabogal F, VanOss Marin B et al. (1987) Development of a short acculturation scale for Hispanics. Hisp J Behav Sci 9, 183-205.

27. Cuellar I, Harris LC \& Jasso R (1980) An acculturation scale for Mexican American normal and clinical populations. Hisp J Behav Sci 2, 199-217.

28. US Census Bureau (2010) American Community Survey 2005-2009. Table: B01001I Sex by age (Hispanic or Latino). https://explore.data.gov/Population/2005-2009-AmericanCommunity-Survey-5-Year-Estimat/jhya-8c2t (accessed October 2012).

29. Martin JA, Hamilton BE, Sutton PD et al. (2010) Births: final data for 2008. Natl Vital Stat Rep 59, 1-72.

30. Ayala GX, Baquero B \& Klinger S (2008) A systematic review of the relationship between acculturation and diet among Latinos in the United States: implications for future research. J Am Diet Assoc 108, 1330-1344.

31. Batis C, Hernandez-Barrera L, Barquera S et al. (2011) Food acculturation drives dietary differences among Mexicans, Mexican Americans, and non-Hispanic whites. J Nutr 141, 1898-1906.

32. Romero-Gwynn E \& Gwynn D (1997) Dietary Patterns and Acculturation Among Latinos of Mexican Descent. JSRI Research Report no. 23. East Lansing, MI: The Julian Samora Research Institute, Michigan State University. 
33. Flores AL, Prue CE \& Daniel KL (2007) Broadcasting behavior change: a comparison of the effectiveness of paid and unpaid media to increase folic acid awareness, knowledge, and consumption among Hispanic women of childbearing age. Health Promot Pract 8, 145-153.

34. Balcázar H, Alvarado M, Hollen ML et al. (2005) Evaluation of Salud Para Su Corazón (Health for Your Heart) National Council of La Raza Promotora outreach program. Prev Chronic Dis 2, 1-9.
35. Lujan J, Ostwald SK \& Ortiz M (2007) Promotora diabetes intervention for Mexican Americans. Diabetes Educ 33, 660-670.

36. Grosse SD, Ouyang L, Collins JS et al. (2008) Economic evaluation of a neural tube defect recurrence-prevention program. Am J Prev Med 35, 572-577.

37. Grosse SD, Flores AL, Ouyang L et al. (2009) Impact of spina bifida on parental caregivers: findings from a survey of Arkansas families. J Child Fam Stud 18, 574-581.

\section{Appendix}

Foods considered to contain corn masa flour, NHANES 2001-2008

Tortilla, corn

Taco shell, corn

Cracker corn (includes stoned corn cracker)

Salty snacks, corn/cornmeal base, nut/nut toasted

Salty snacks, corn or cornmeal, corn chips, cheese

Salty snacks, corn or cornmeal, corn puffs, twists

Salty snacks, corn or cornmeal, tortilla chips

Salty snacks, corn/corn-cheese chips, unsalted

Salty snacks, corn/cornmeal base, tortilla chips light

Salty snacks, tortilla chips, fat free, with Olean

Salty snacks, corn/cornmeal base, tortilla, low fat, baked

Salty snacks, corn/cornmeal, tortilla, low fat, baked, no salt

Salty snacks, corn/cornmeal base, with oat bran, tortilla chips

Salty snacks, corn based/cheese puffs \& twists, low fat

Tortilla chips, unsalted

Corn flour patties or tarts, fried

Nachos with beef, beans, cheese \& sour cream

Nachos with cheese \& sour cream

Nachos with cheese, meatless, no beans

Nachos with beans, no cheese

Nachos with beans \& cheese

Nachos with beef, beans \& cheese

Nachos with beef \& cheese

Nachos with chilli

Nachos with beef, beans, cheese, tomatoes \& onions

Nachos with chicken/turkey \& cheese

Enchilada with beef, no beans

Enchilada with beef \& beans (includes enchilada, not further specified)

Enchilada with beef, beans \& cheese

Enchilada with beef \& cheese, no beans

Enchilada with ham \& cheese, no beans

Enchilada with chicken, tomato-base sauce

Enchilada with chicken \& beans, tomato-base sauce

Enchilada with chicken, beans \& cheese, tomato-base sauce

Enchilada with chicken \& cheese, no beans, tomato-base sauce

Enchilada with beans, meatless

Enchilada with beans \& cheese, meatless

Enchilada with cheese, meatless, no beans

Enchilada with seafood, tomato sauce

Beef enchilada dinner, not further specified (frozen meal)

Beef enchilada, gravy, rice, refried beans (frozen)

Cheese enchilada with beans \& rice (frozen meal)

Cheese enchilada (frozen meal)

Chicken enchilada (diet frozen meal)

Chicken enchilada with salsa, rice, vegetables, dessert (diet frozen)

Chilaquiles, tortilla casserole with salsa, cheese \& egg

Chilaquiles, tortilla casserole, no egg

Pochito (frankfurter/hot dog \& beef chilli in tortilla)

Huevos rancheros

Mexican casserole with beef \& beans

Mexican casserole with beef (includes frito pie, not further specified)

Sopa de tortilla, Mexican-style tortilla soup

Tamale with meat \&/or poultry (includes tamale, not further specified)

Tamale, meatless, Caribbean or Puerto Rican style

Tamale, plain, meatless, no sauce, Mexican

Tamale casserole with meat

Tamale casserole, Puerto Rican (tamales en cazuela)

Tamale in a leaf, Puerto Rican (tamales en hoja) 
Tamale, sweet

Tamale, sweet, with fruit

Tamale with meat

Tamale with chicken

Tamale, plain, meatless, no sauce, Puerto Rican style

Pupusa, cheese-filled

Pupusa, meat-filled

Pupusa, bean-filled

Chalupa with beans, cheese, lettuce $\&$ tomato

Chalupa with beef, cheese, lettuce, tomato \& sour cream

Chalupa with beef, cheese, lettuce, tomato \& salsa

Chalupa with beans, chicken \& cheese

Chalupa with chicken, cheese, lettuce, tomato \& sour cream

Chalupa with chicken, cheese, lettuce, tomato \& salsa

Gordita/sope shell, plain no filling, grill, no fat added

Gordita/sope shell, plain, no filling, fried in oil

Quesadilla with cheese, meatless

Quesadilla with meat \& cheese

Quesadilla with poultry \& cheese

Taco/tostada with beef, cheese \& lettuce

Taco/tostada with beef, lettuce, tomato \& salsa

Taco/tostada with beef, cheese, lettuce, tomato \& salsa

Taco with beef, cheese, lettuce, tomato \& sour cream

Soft taco with beef, cheese \& lettuce (includes Taco Bell)

Soft taco with chicken, cheese \& lettuce

Soft taco with chicken, cheese, lettuce, tomato \& sour cream

Taco/tostada with chicken/turkey, lettuce, tomato \& salsa

Soft taco with beef, cheese, lettuce, tomato \& salsa

Soft taco with bean, cheese \& lettuce

Soft taco with bean, cheese, lettuce, tomato \&/or salsa

Soft taco with bean, cheese, lettuce, tomato \&/or salsa, sour cream

Taco/tostada with fish

Taco/tostada with chicken, cheese, lettuce, tomato \& salsa

Taco/tostada with beans, meatless, lettuce, tomato \& salsa

Taco/tostada with beans, cheese, lettuce, tomato \& salsa

Taco/tostada with beans, cheese, meat, lettuce, tomato \& salsa

Taco salad with beef \& cheese, corn chips

Flauta, not further specified

Flauta with beef

Flauta with chicken

Taquitos

Taquitos with meat

Taquitos with chicken

Taco with crab meat, Puerto Rican (tacos de jueyes)

Atole (cornmeal beverage)

NHANES, National Health and Nutrition Examination Survey. 